LAWRENCE LIVERMORE NAT IO N A L LABORATORY

\title{
Technology Base 2004 Report on the Ultrasonic Calibration Test Phantom
}

Sean K. Lehman, Karl A. Fisher, Mick Werve, David H. Chambers

September 29, 2004 
This document was prepared as an account of work sponsored by an agency of the United States Government. Neither the United States Government nor the University of California nor any of their employees, makes any warranty, express or implied, or assumes any legal liability or responsibility for the accuracy, completeness, or usefulness of any information, apparatus, product, or process disclosed, or represents that its use would not infringe privately owned rights. Reference herein to any specific commercial product, process, or service by trade name, trademark, manufacturer, or otherwise, does not necessarily constitute or imply its endorsement, recommendation, or favoring by the United States Government or the University of California. The views and opinions of authors expressed herein do not necessarily state or reflect those of the United States Government or the University of California, and shall not be used for advertising or product endorsement purposes.

This work was performed under the auspices of the U.S. Department of Energy by University of California, Lawrence Livermore National Laboratory under Contract W-7405-Eng-48. 


\title{
Technology Base 2004 Report on the Ultrasonic Calibration Test Phantom
}

\author{
Sean K. Lehman, Karl A. Fisher, Mick Werve, David H. Chambers
}

September 28, 2004

Tech Base 2004 


\section{Project Overview}

We designed and built a phantom consisting of vertical wires maintained under tension to be used as an ultrasonic test, calibration, and reconstruction object for the LLNL annular array scanner known as the KCI scanner. We provide a description of the phantom, present some example data sets, and preliminary reconstructions.

\section{Project Goals}

Design and build a reconfigurable ultrasonic phantom for the KCI scanner. Use it to collect well characterized data under controlled conditions for use as "canonical data sets" in testing and evaluating new inversion algorithms.

\section{Relevance to LLNL Mission}

The non-destructive evaluation (NDE) of objects and media of interest to LLNL/DOE/DOD is an essential part of LLNL's mission. Many NDE situations have put demands beyond the scope of the current suite of imaging algorithms. As new algorithms and codes come on line, they must be evaluated on well characterized phantoms. The Ultrasonic Calibration Test Phantom provides such a data set.

\section{FY04 Accomplishments and Results}

We designed and built a phantom consisting of vertical wires maintained under tension to be used as an ultrasonic test, calibration, and reconstruction object for the LLNL annular array scanner known as the KCI scanner. The phantom consists of top and bottom plates into which are drilled holes through which the wires are run. The holes form a geometrical pattern which govern the horizontal distribution of the wires. The plates are affixed to top and bottom mounting brackets which are pulled apart putting the wires under tension. Given that the phantom object formed by the wire distribution does not vary much in the vertical ( $z$-direction), we assume the measured data are from a 2.5-dimensional object. The initial conceptual phantom design is presented in Figure 1

These plates are removable permitting differing designs to be used. We currently only have one design: a logarithmic spiral with equation,

$$
\mathbf{r}\left(\theta_{n}\right)=a\left(\cos \left(\theta_{n}\right), \sin \left(\theta_{n}\right)\right) e^{b \theta_{n}}
$$


where

$$
\begin{aligned}
a & \equiv \lambda_{0} & & \text { is the initial radius and, } \\
\lambda_{0} & \equiv v_{0} / f_{0} & & \text { is the insonifying wavelength, } \\
v_{0} & \equiv 1500 \mathrm{~meters} / \text { second } & & \text { is the assumed background water velocity, } \\
f_{0} & \equiv 1 \mathrm{MHz} & & \text { is the approximate insonifying frequency, } \\
b & \equiv 10 \pi / 180 & & \text { is the spiral growth rate, } \\
\theta_{n} & \equiv\{n \Delta \theta\}_{n=0}^{N-1} & & \text { are the angular locations of the wires, } \\
\Delta \theta & \equiv 30 \pi / 180 & & \text { is the angular increment, } \\
N & \equiv 31 & & \text { is the number of wires. }
\end{aligned}
$$

This current configuration is shown in Figure 2(a). We have allowed for an optional acrylic hollow cylinder around the phantom as shown in Figure 2(b). Figure 2(c) shows one of the plates.

The phantom is fastened into the scanner: the top block is affixed to a rod fastened to the central bore of the scanner drive; the bottom block is fastened to the bottom of the tank. Once installed, the blocks are pulled apart to render the wires taut. Figure 3 (a) shows the phantom with 31 steel taut wires. Figure 3 (b) shows the optional acrylic cylinder in place.

Figures 4 and 5 show measured time series data and spectra for the water background and 31 steel wire cases. The data are very clean. Clear and distinct sinograms of individual wires are seen in Figure 5.

The design of the phantom allows for wire of different materials to be used. We have run scans with the following combinations:

- 31 steel wires;

- 30 steel, 1 nylon;

- 25 steel, 6 nylon;

- 25 steel, 6 nylon, with the hollow cylinder;

- 2 steel, 2 nylon resolution pair;

- 2 steel, 2 nylon resolution pair, with the hollow cylinder;

- Hollow cylinder only (no wires).

Preliminary reconstructions, using Quantitative Time-Domain Multiview Imaging (QMTDI), of the 30 steel/1 nylon and 25 steel/6 nylon combinations are shown in Figures 6 and 7.

\section{Future Work}

We are very pleased with the phantom design and quality of the measured data which will be used as "canonical data sets" for testing new inversion and detection algorithms. The flexibility of the phantom allows us to design new models to simulate real NDE problems of interest to LLNL, DOE, and DOD. Additionally, we will share these data sets with outside collaborators such as those at the Center for Subsurface Sensing and Imaging Systems (CenSSIS) in order to identify researchers who have NDE solutions of interest to LLNL.

We will be reconstructing the current data sets with our three current, mature algorithms:

- Time reversal (TR) [1]; 
- Hilbert space inverse wave (HSIW) [2, 3];

- Quantitative Time-Domain Multiview Imaging (QMTDI) (reference currently being prepared for publication).

\section{References}

[1] S. K. Lehman and A. J. Devaney. Transmission mode time-reversal super-resolution imaging. The Journal of the Acoustical Society of America, 113(5):2742-2753, May 2003.

[2] A. J. Devaney and M. Dennison. Inverse scattering in inhomogeneous background media. Inverse Problems, 19:855-870, 2003.

[3] S. K. Lehman and S. J. Norton. Radial reflection diffraction tomography. The Journal of the Acoustical Society of America, 116(4), October 2004. 


\section{Side View}

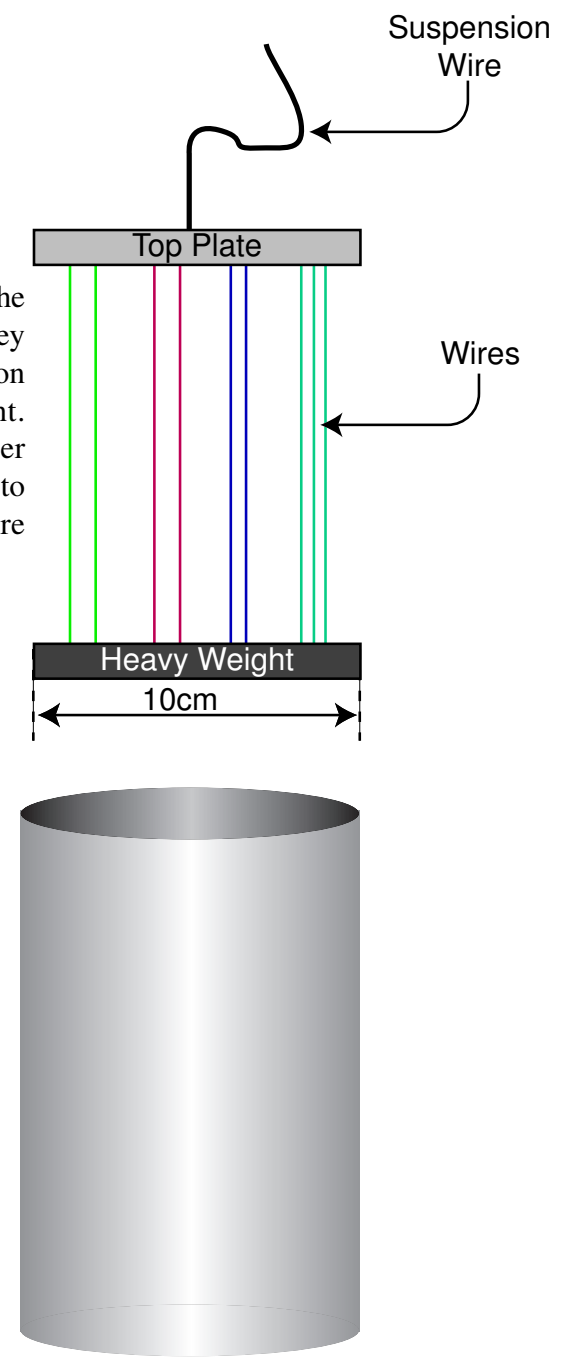

\section{Top View}

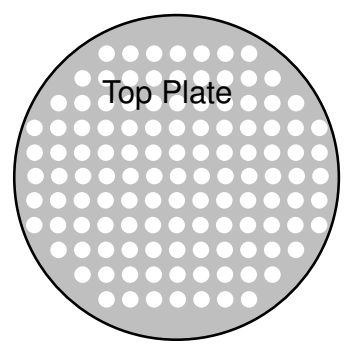
are suspended under tension by the bottom weight. Beads, spheres, and other objects can be fastened to the wires to model more complicated structures.

Removable outer cylinder. Slips over the suspended wire phantom. Data will be collected without and with the sheath.

The sheath will be fastened to the weight in a water tight manner. The phantom may then be filled with a contrast agent.

Figure 1: Preliminary wire phantom conceptual design. 


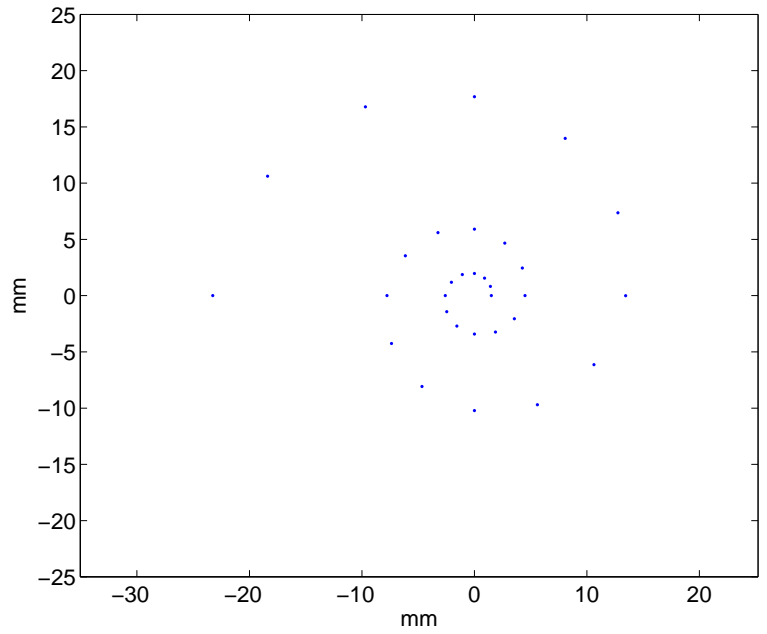

(a)

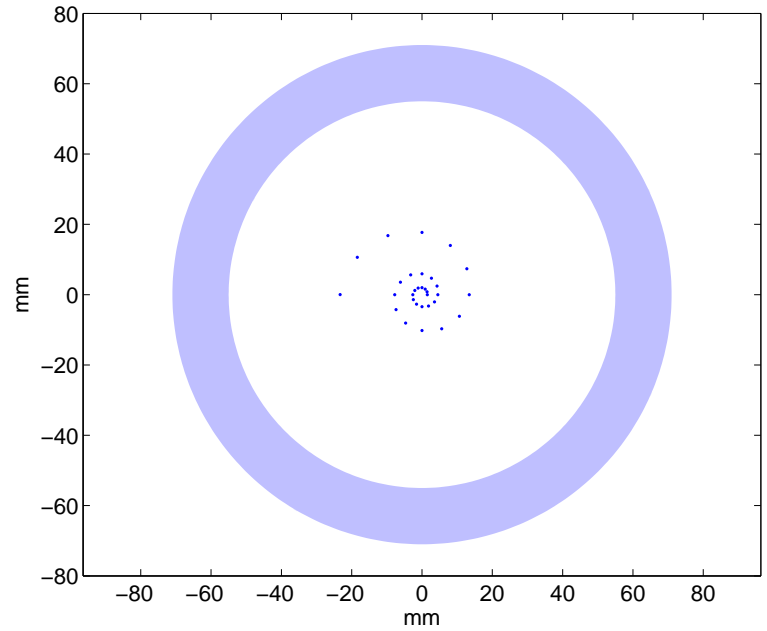

(b)

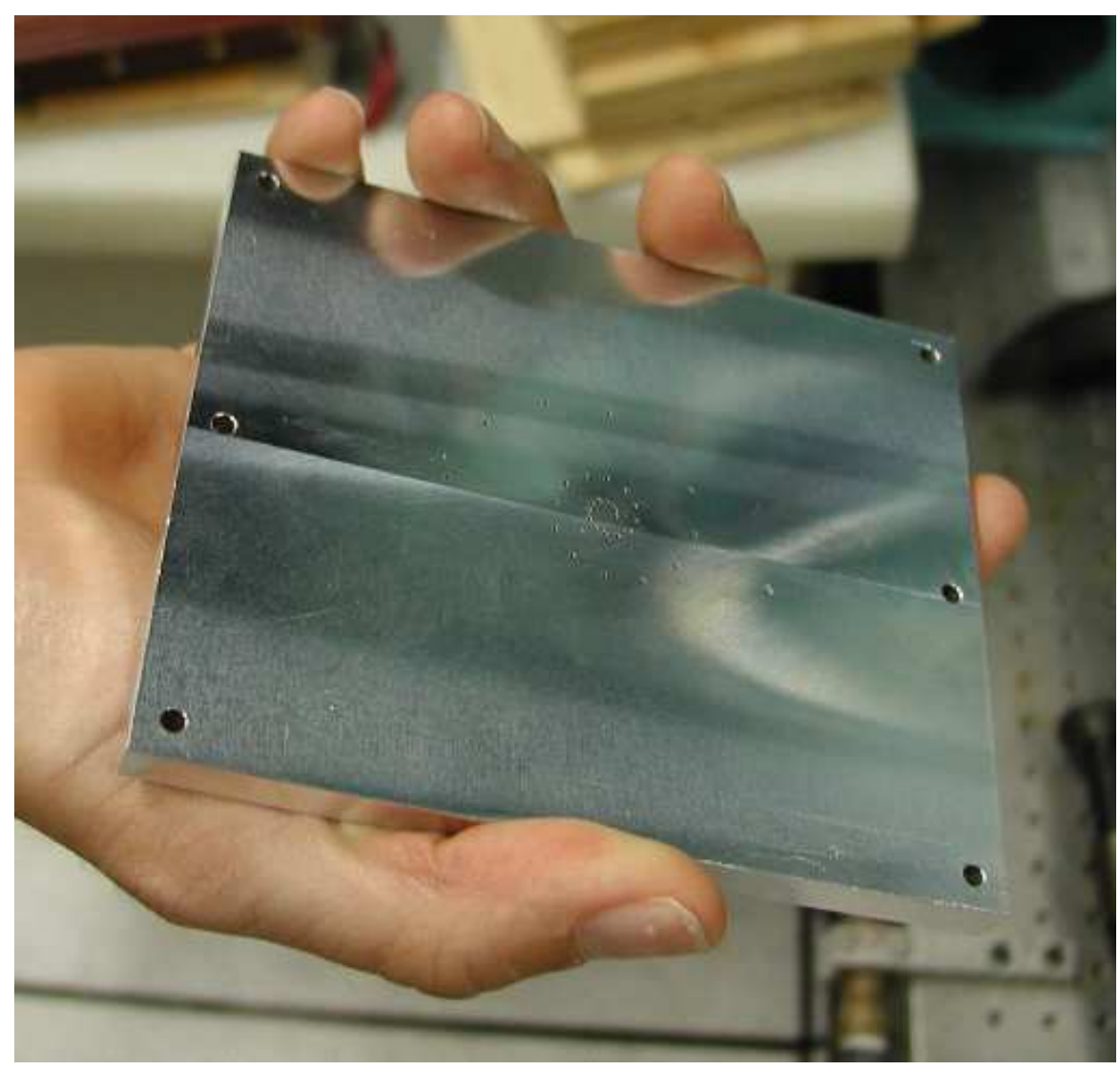

(c)

Figure 2: Basic spiral phantom design. (a) Without hollow cylinder. (b) With cylinder. (c) Photograph of wiring plate with holes. 


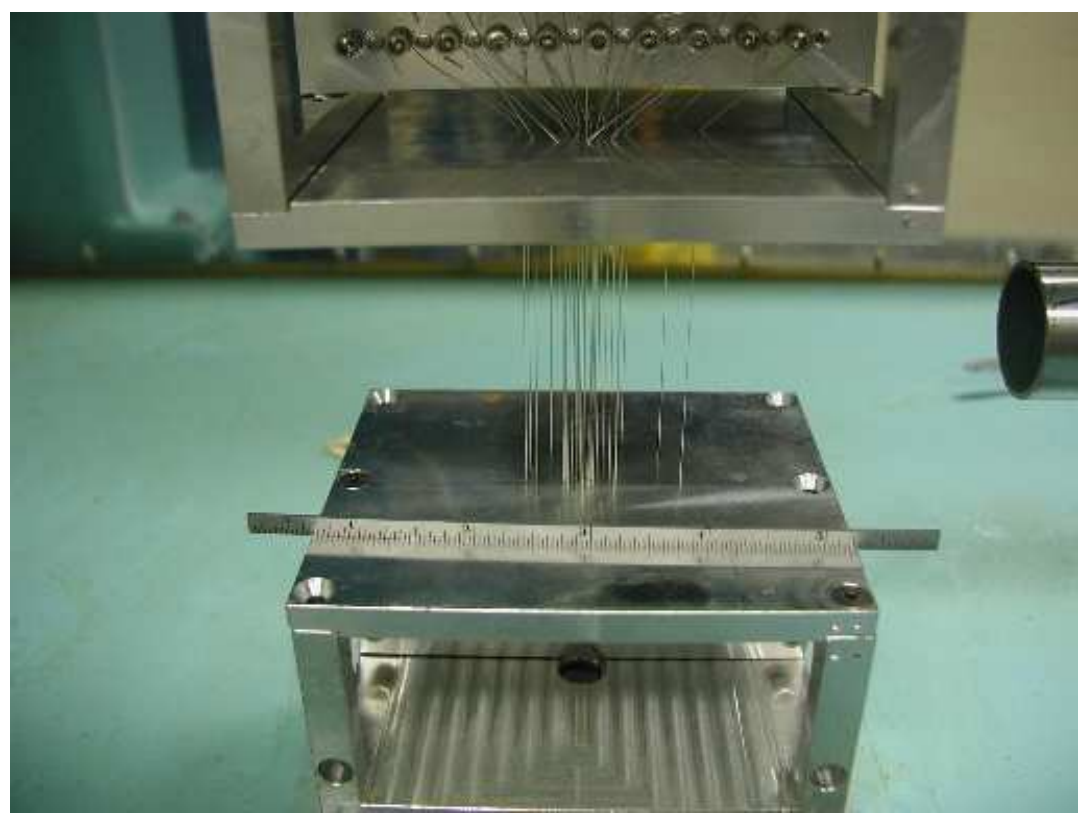

(a)

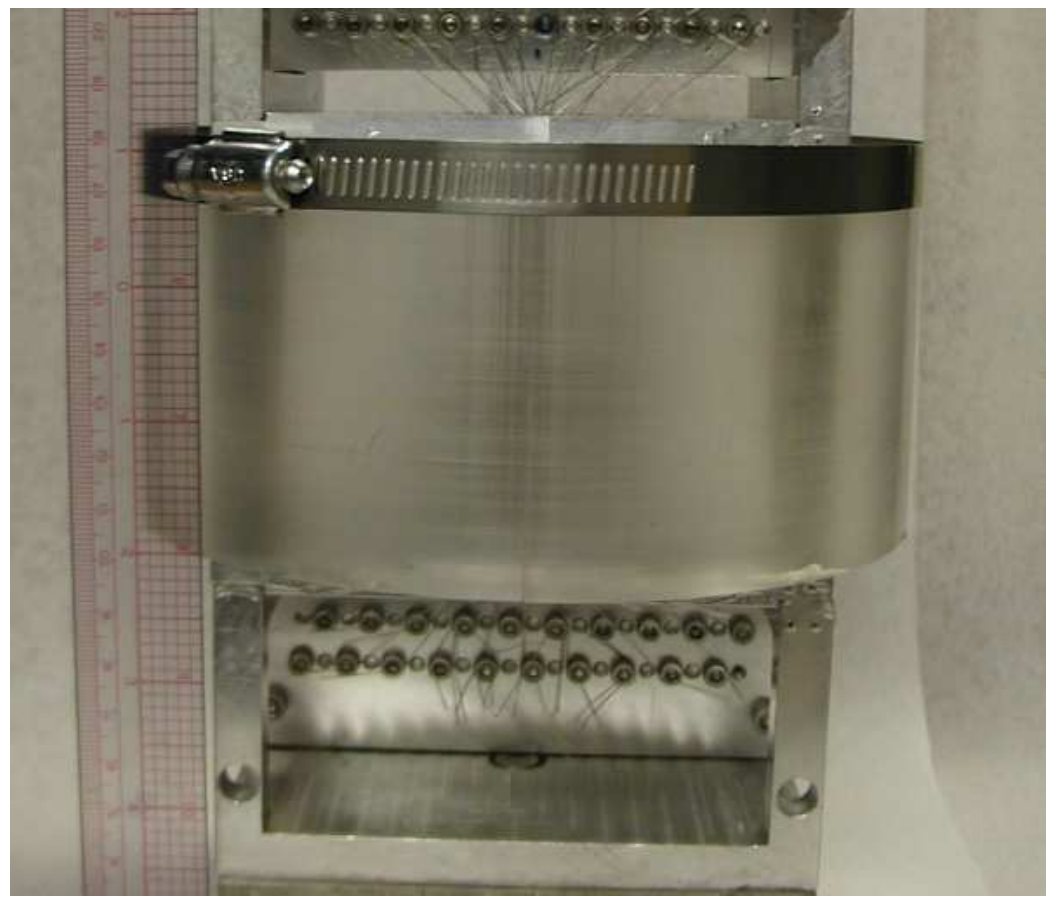

(b)

Figure 3: (a) Phantom after the wires were pulled taut. (b) Phantom with optional acrylic hollow cylinder. 

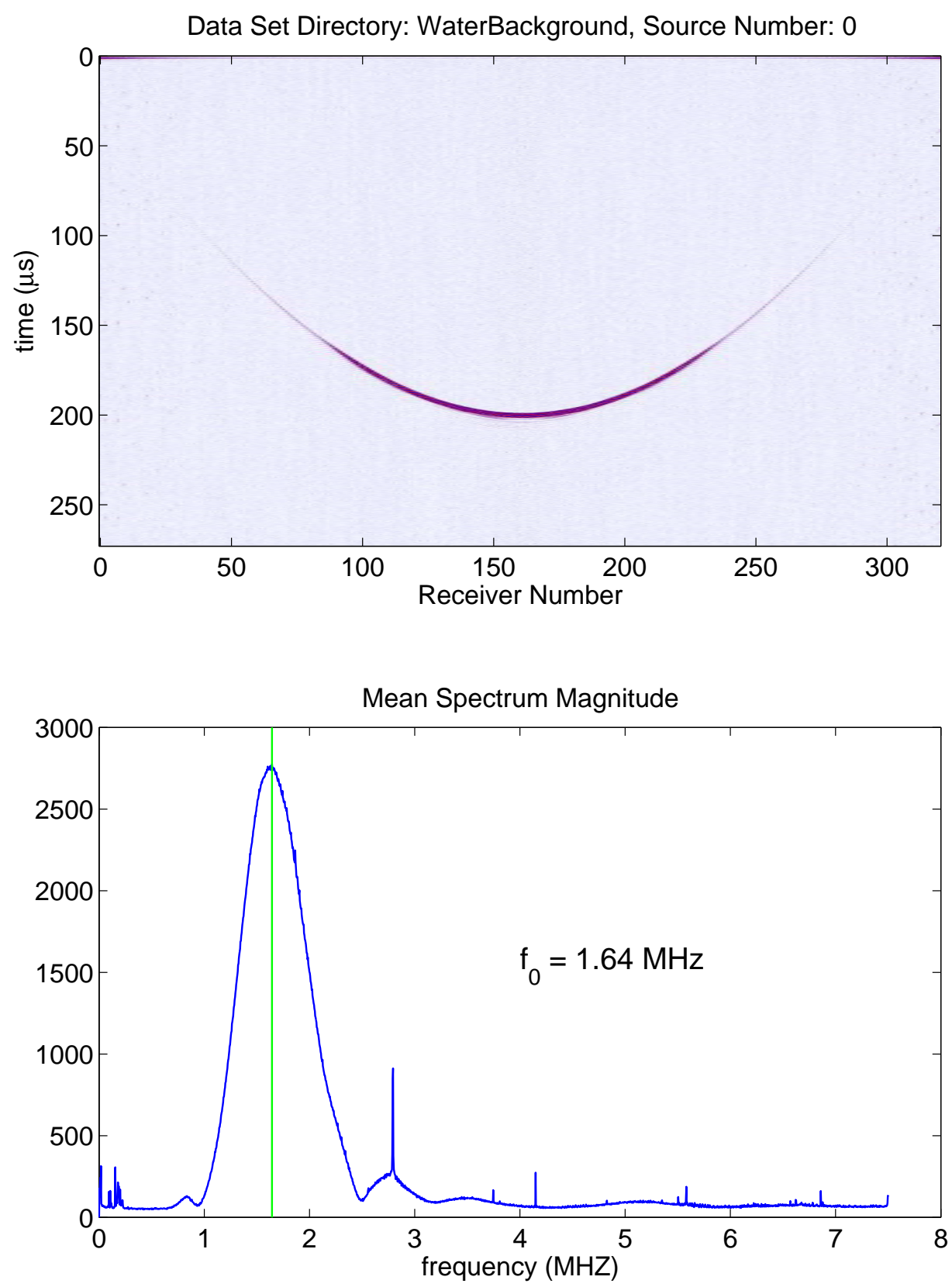

Figure 4: Water background. 

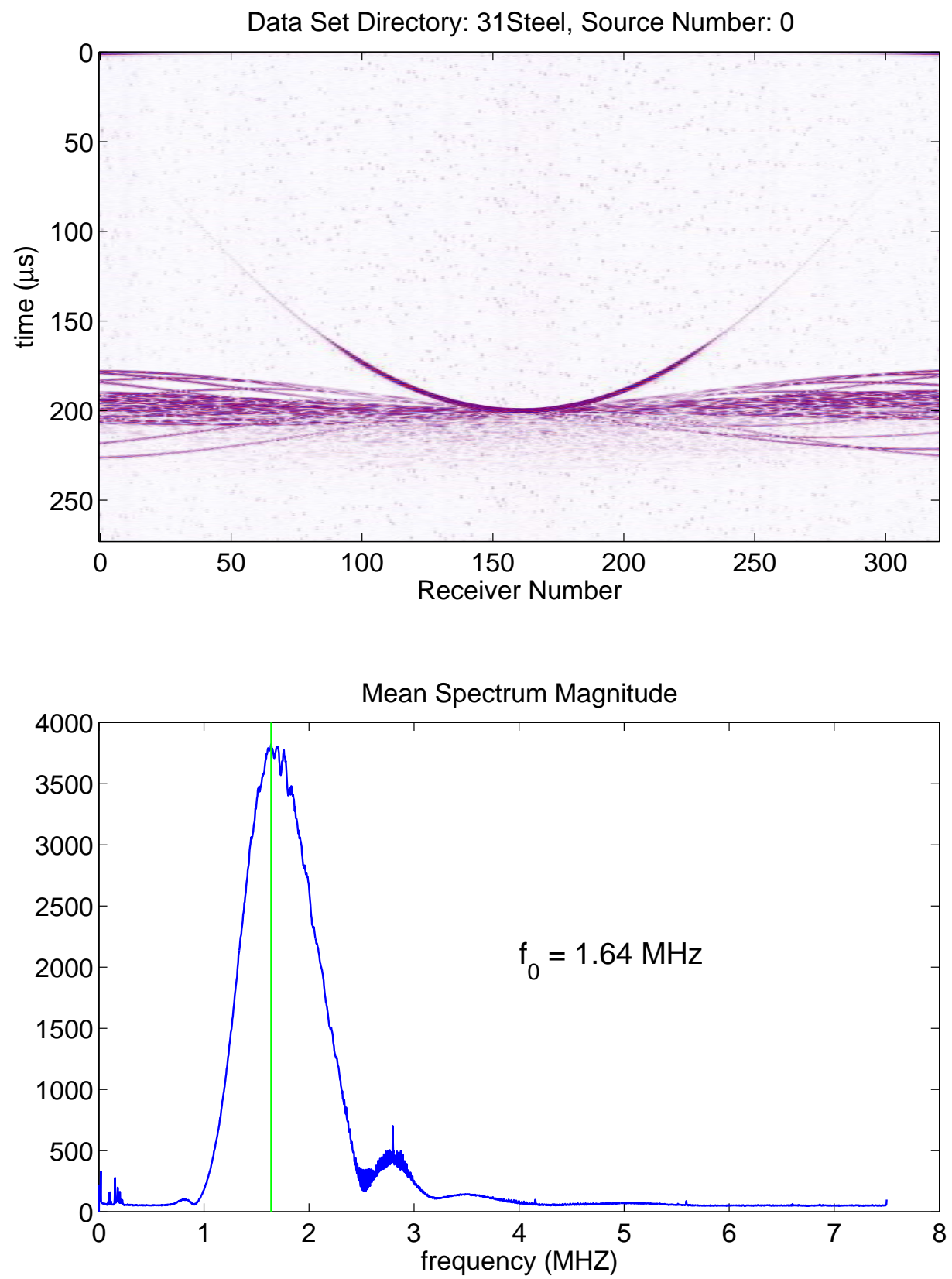

Figure 5: 31 steel wires. 


\section{Full Image}
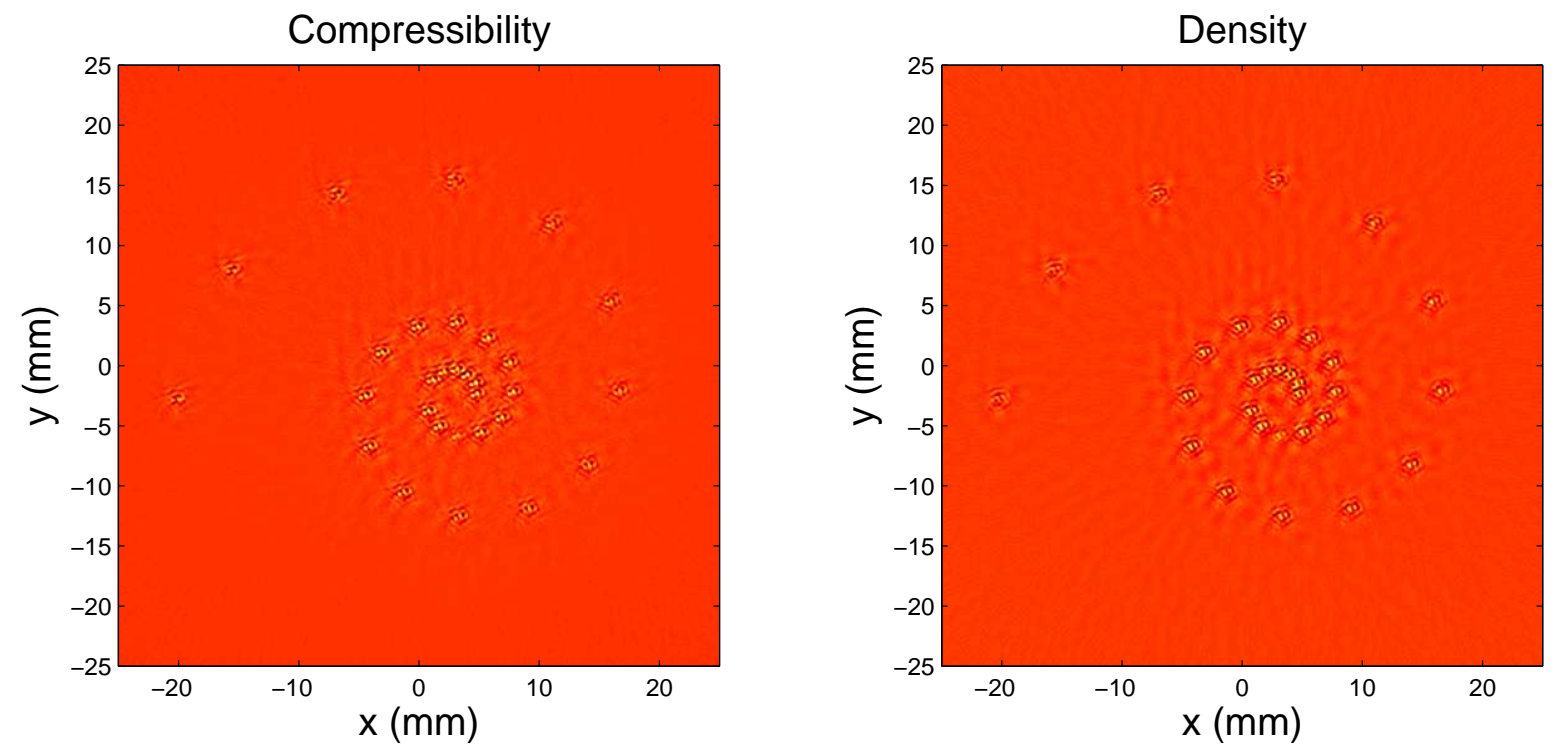

\section{Detail of Center}
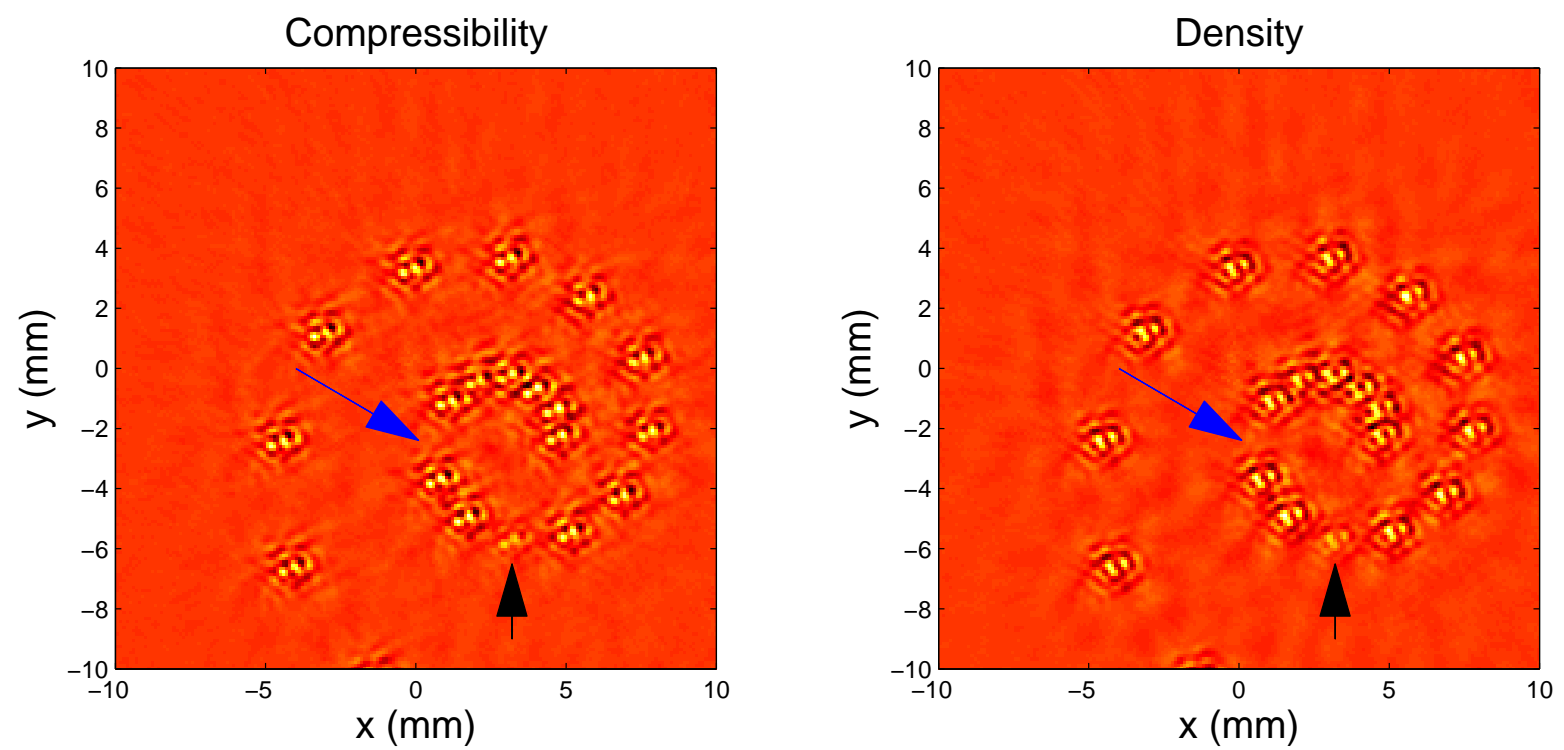

Figure 6: Preliminary reconstructions using Quantitative Time-Domain Multiview Imaging (QMTDI) method of one nylon wire case. The nylon wire is located at the 6 o'clock position on the inner most spiral arm as indicated by the black arrow. The blue arrow indicates the location of a missing wire at the 9 o'clock position. 

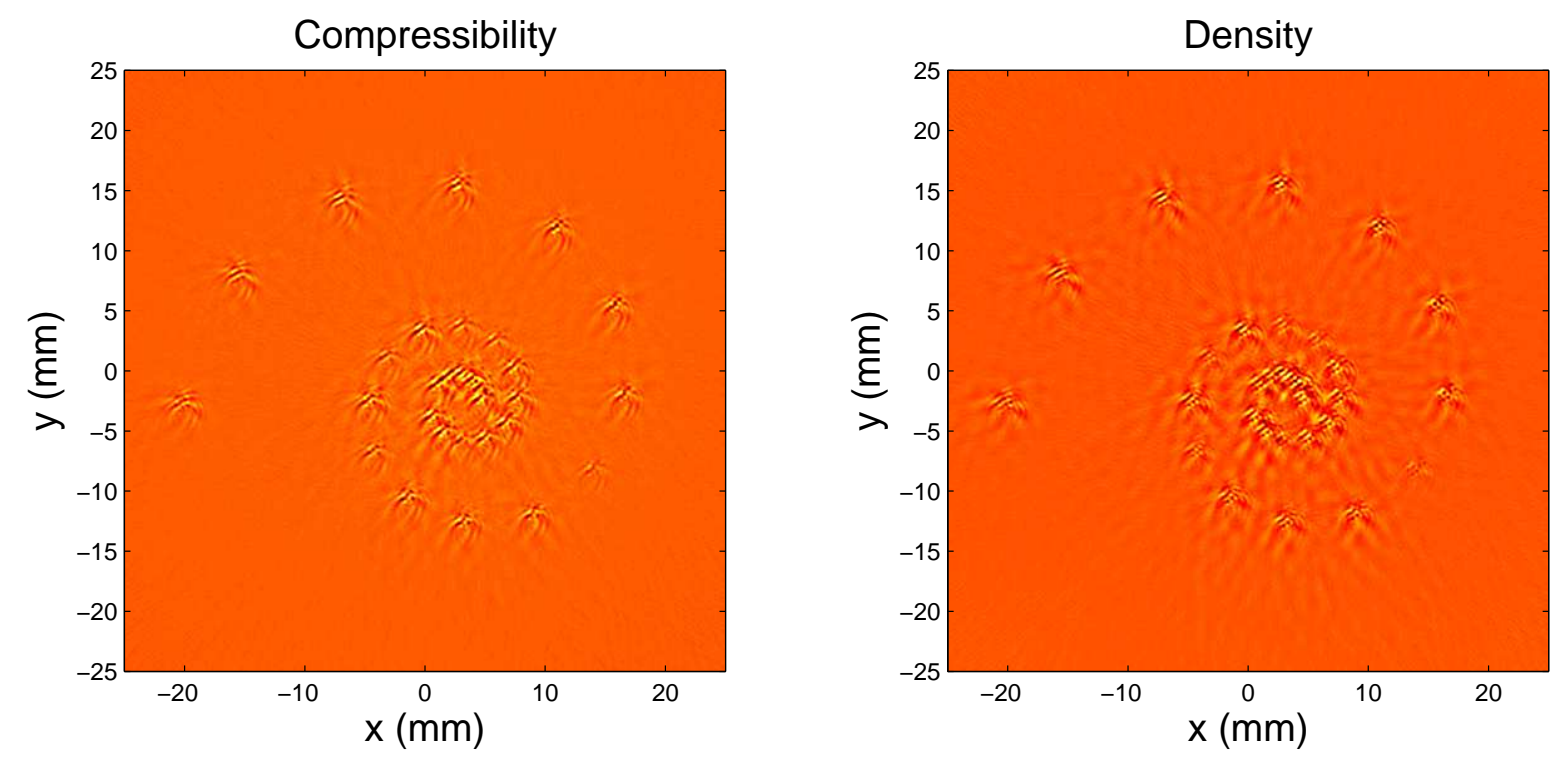

\section{Detail of Center}
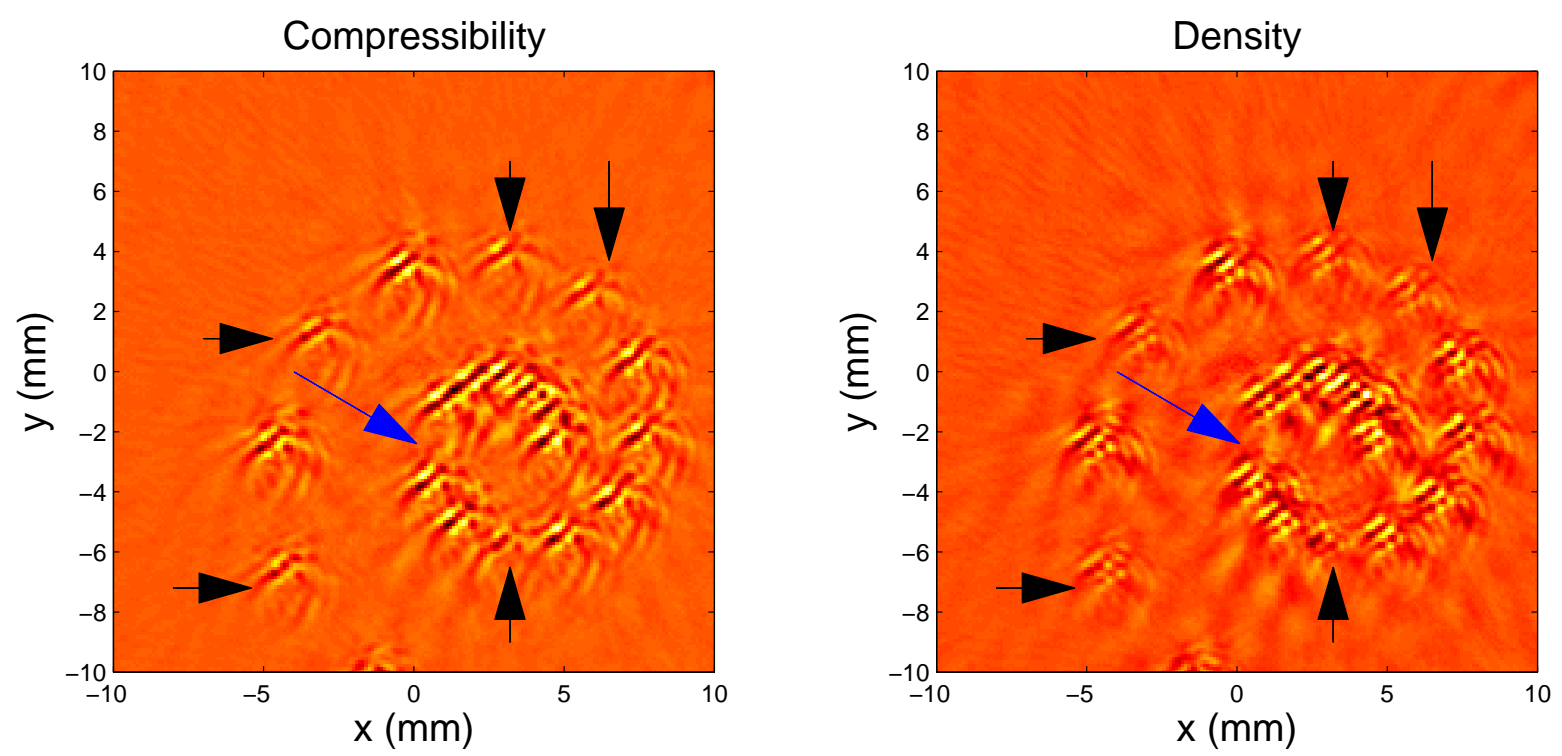

Figure 7: Preliminary reconstructions using Quantitative Time-Domain Multiview Imaging (QMTDI) method of six nylon wire case. The black arrows indicate the locations of the nylon wires. The blue arrow indicates the location of a missing wire at the 9 o'clock position. 